\title{
Research in Autodesk Inventor weldment performance cultivator frame
}

\author{
V V Telegin ${ }^{1,2}$ and I V Telegin ${ }^{1}$ \\ ${ }^{1}$ Lipetsk State Technical University, 30, Moskovskaya str., Lipetsk, 398055, Russia \\ E-mail: ${ }^{2}$ vv.telegin@yandex.ru,
}

\begin{abstract}
The paper examines issues of calculation in the welded frame structures design of engineering objects using as the example optimizing the cultivator frame. Design environment - Autodesk Inventor Professional. The purpose of the study was to reduce the cost of the base product. The basis for solving this problem is the development solid-state model of the cultivator frame basic construction; strength calculation of the frame with various options for its loading; the choice of the application of forces to the frame, leading to the occurrence of maximum stresses in the frame elements; the use of this option to analyze the strength of the frame after making changes to its design. In this paper, we investigated the possibility of replacing the steel grade of which the frame beams are made with St3ps steel; the possibility of making frame beams from a steel roll-formed channel is investigated. The possibility of reducing more than 30 percent of the frame mass by means of implementing the indicated actions is substantiated.
\end{abstract}

\section{Introduction}

One of the main requirements for engineering products being designed is their minimum metal consumption and cost [1-3]. The metal consumption of the frame structure considered in this paper depends on the geometry of the profile (tube, channel, I-beam, etc.) and the size of its cross section. The cost, in addition, is associated with the cost of the material - the steel grade from which it (the frame) is made.

The strength of the structure [4, 5], its indicator is the safety factor. This indicator is considered in this work as the only one that determines the performance of the product. In practice, of course, this is not so. The ability of the product to perform its functions depends on its geometry, magnitude of the elastic deformations, dynamic and static processes that arise during the product operation [6,7], and many other factors.

Traditionally, the calculation of the safety factor is performed by the methods of materials resistance $[1,2]$. Methods, in the general case, are rather laborious and not very accurate. The modern way is the finite element method (FEM) [8-10]. In combination with solid state design, FEM (and its modifications) is the basis of present design.

Autodesk Inventor Professional [11, 12], used in this work to calculate the frames of cultivators, is one of the most famous software products combining methods of solid modeling, development of design documentation and strength calculations based on FEM. 


\section{Research problem statement}

The solid-state model of the cultivator is shown in figure 1. Its frame is a welded structure made of square tubes [13]. The task is to consider the possibility of using other beams profiles of lower mass and made of cheaper steel grades in the frame design.

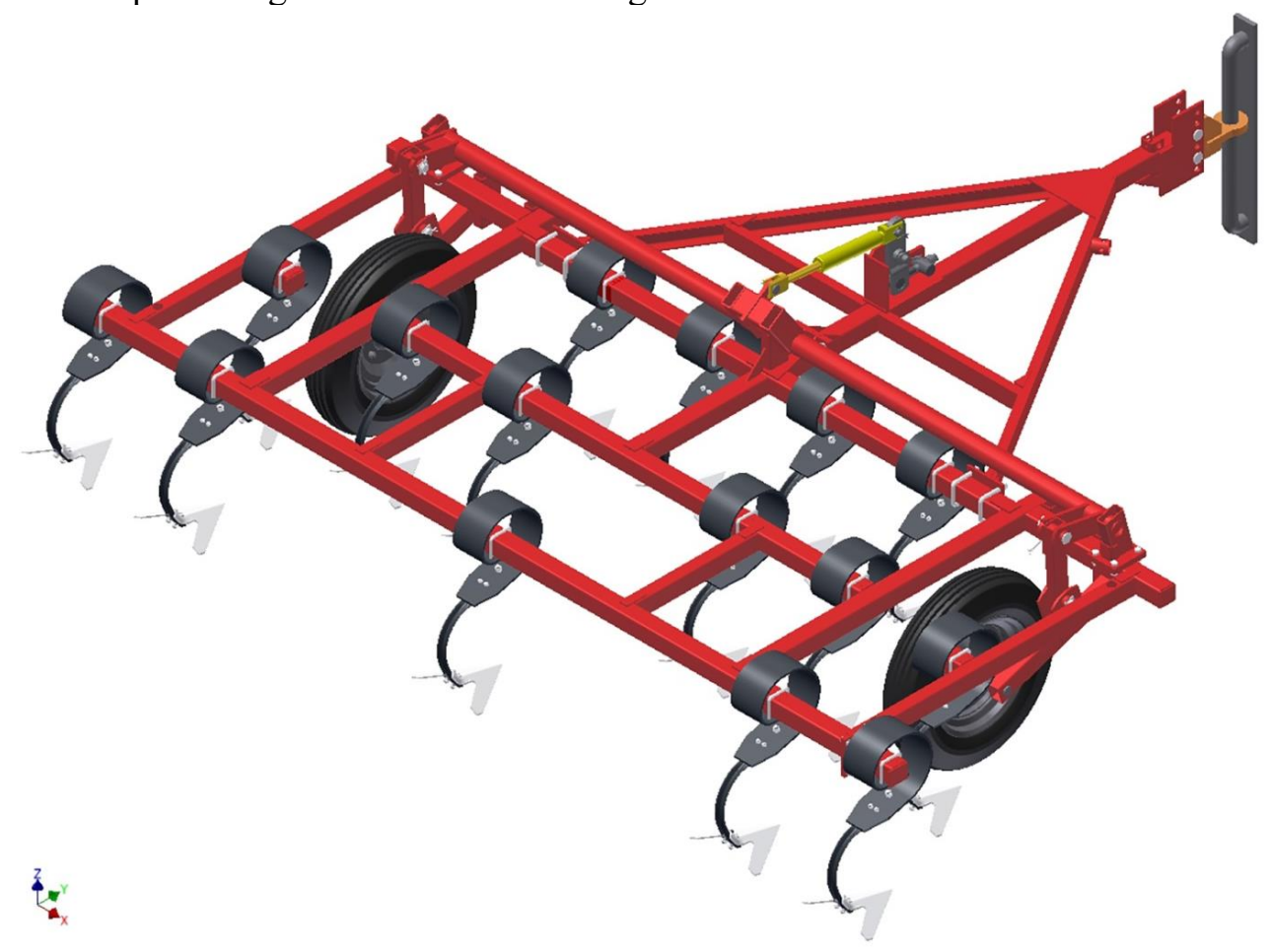

Figure 1. Solid-state cultivator model: frame, suspension, traction device.

When the cultivator is working, stresses arise in the elements of its frame, the values of which are various in different structural elements. In this regard, the following stages of upgrading the frame design are proposed:

- the study of the stress-strain state of the cultivator frame with various schemes of application of forces, in order to identify the least loaded parts;

- evaluation of the possibility to replace individual lightly-loaded frame elements with cheaper profiles or even their exclusion from the design;

- changing the design of the frame and the study of its performance.

\section{Cultivator frame design model}

Figure 2 shows the calculated model of the cultivator frame. Unlike the actual design, the device for coupling the frame and the traction device (tractor) is simplified and serves only for the correct application of the traction force highlighted in red. Instead of a real suspension, its simplified model is used, which allows simulating the application of the force highlighted in yellow to the suspension leg from the ground at any angle or impose a pinch dependence. These elements highlighted in figure 2 in blue are not objects of study. In the presented results of the frame simulation by the finite element method, their display, as well as the display of the applied forces, is hidden.

In the process of a comprehensive study of the strength of the cultivator frame, several (more than ten) variants of its load were studied, differing in the angle of application of the traction force ( 0 or 30 degrees), the choice of suspension for imposing a fixation dependence and the direction of the forces acting on the suspension ( 0 or 180 degrees). 
Traction force in all variants of the study is taken equal to $60 \mathrm{kN}$. In reality, its value is from 18 to $27 \mathrm{kN}$. The force acting on the suspension is $3 \mathrm{kN}$. In the absence of suspension paw engagement for some kind of obstacle, this value is the maximum possible.

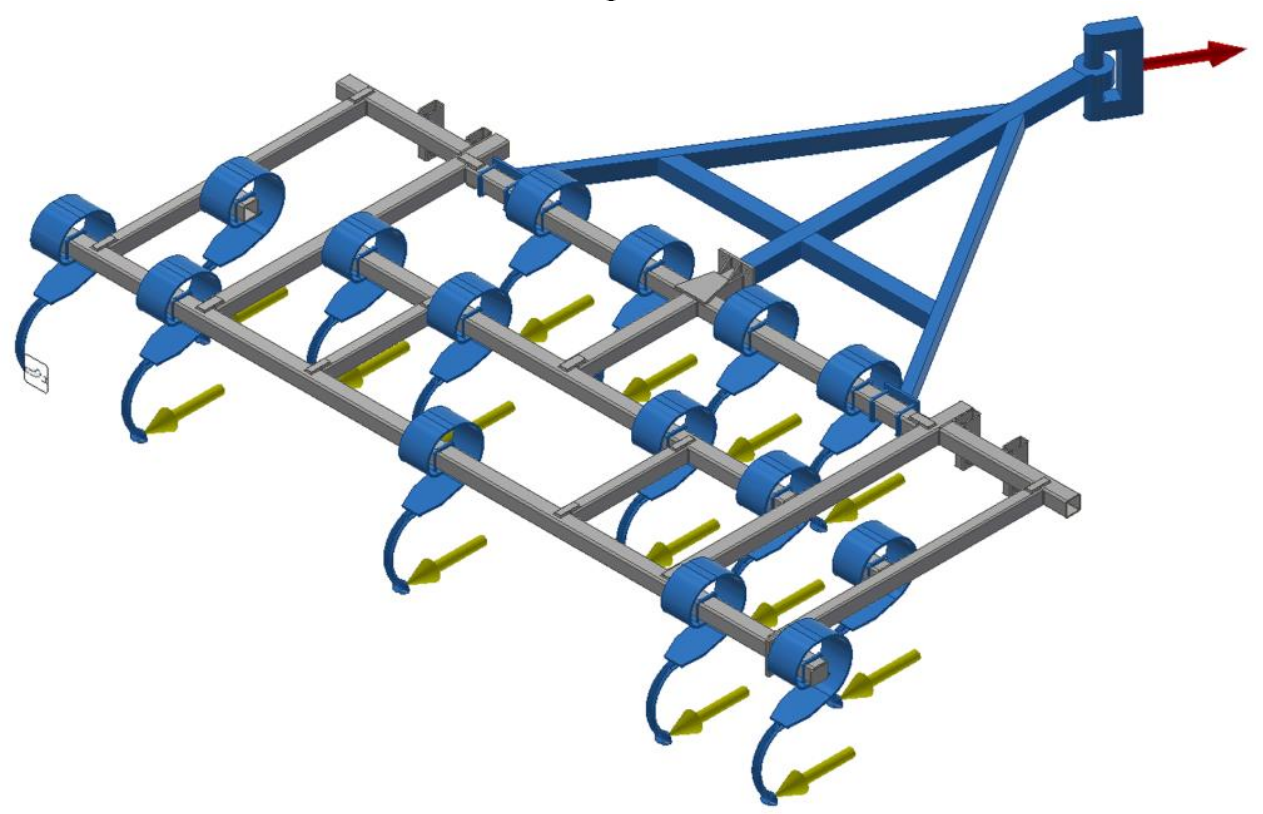

Figure 2. Calculation model of the cultivator frame.

\section{Results and discussion}

As an example, the article presents a variant with the minimum calculated values of the safety factor in the frame beams and their joints (figures 2 and 3).

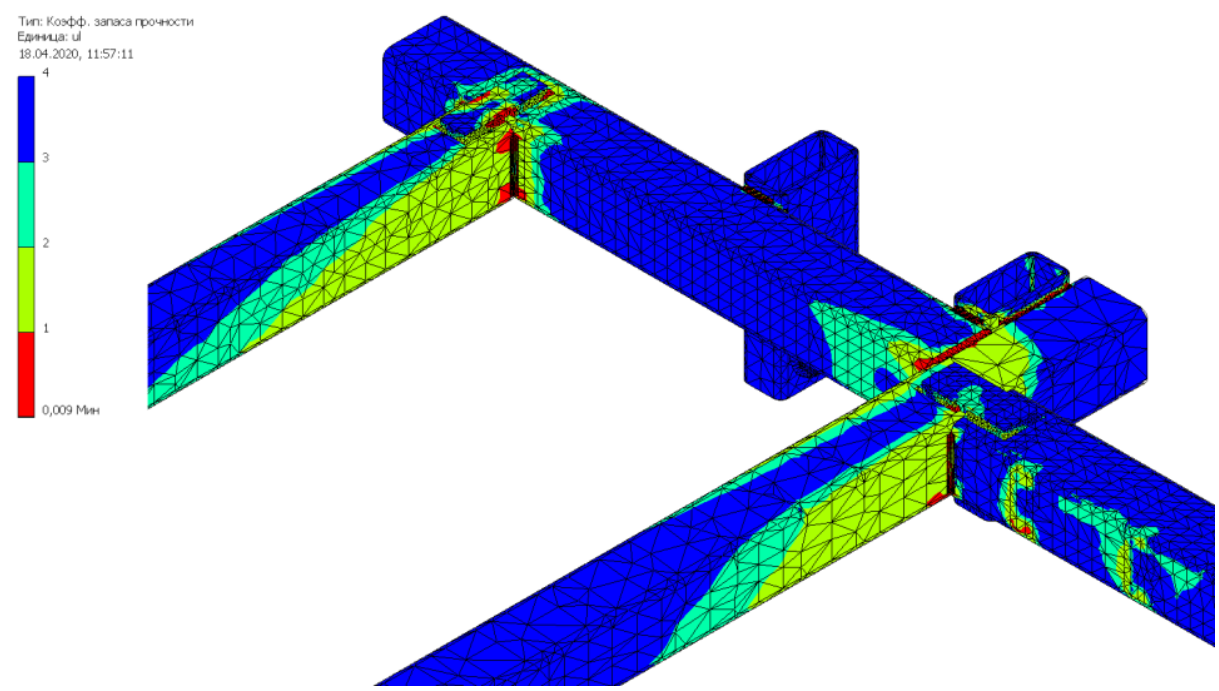

Figure 3. Calculation of safety factor.

As follows from the research results, the basic design of the cultivator frame has a margin of safety significantly exceeding the required. An exception is welds. This is explained by the feature of the calculated solid-state frame model. During its development, the direct impact of beams and overlays forming the welded frame structure on each other is excluded. The interconnection of the frame elements with each other is carried out only through the rollers of the welds. This feature allows you to additionally identify problem areas associated with the connection of parts by welding. 
The results of the study suggest a slight loss of frame strength when using profiles made of cheaper material. In turn, such a replacement will have a positive effect on reducing the total cost of product. In figure 4 shows the structural strength analysis results of the frame made of steel grade - St3ps [14]. Traction force in this case is taken equal to $30 \mathrm{kN}$. Its maximum value recommended by the manufacturer is $27 \mathrm{kN}$.

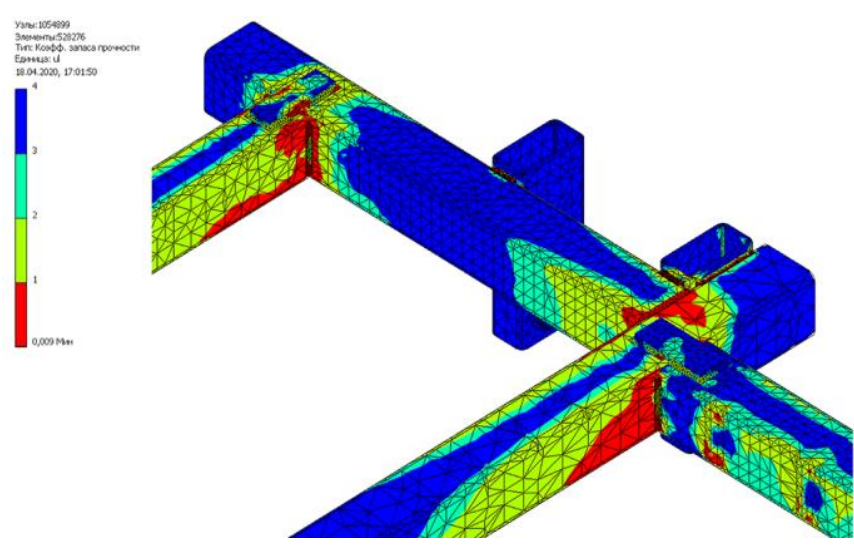

(a)



(b)

Figure 4. Calculation of the safety factor of the frame structure made of steel grade St5ps. The value of traction force: (a) $-60 \mathrm{kN},(\mathrm{b})-30 \mathrm{kN}$.

In figure 5 shows a fragment of a cultivator frame made of channels [15], and the result of calculating the strength with a traction force value of $30 \mathrm{kN}$. Unlike the previous figures, for a more visual representation of the design, the frame is rotated 180 degrees (bottom view).

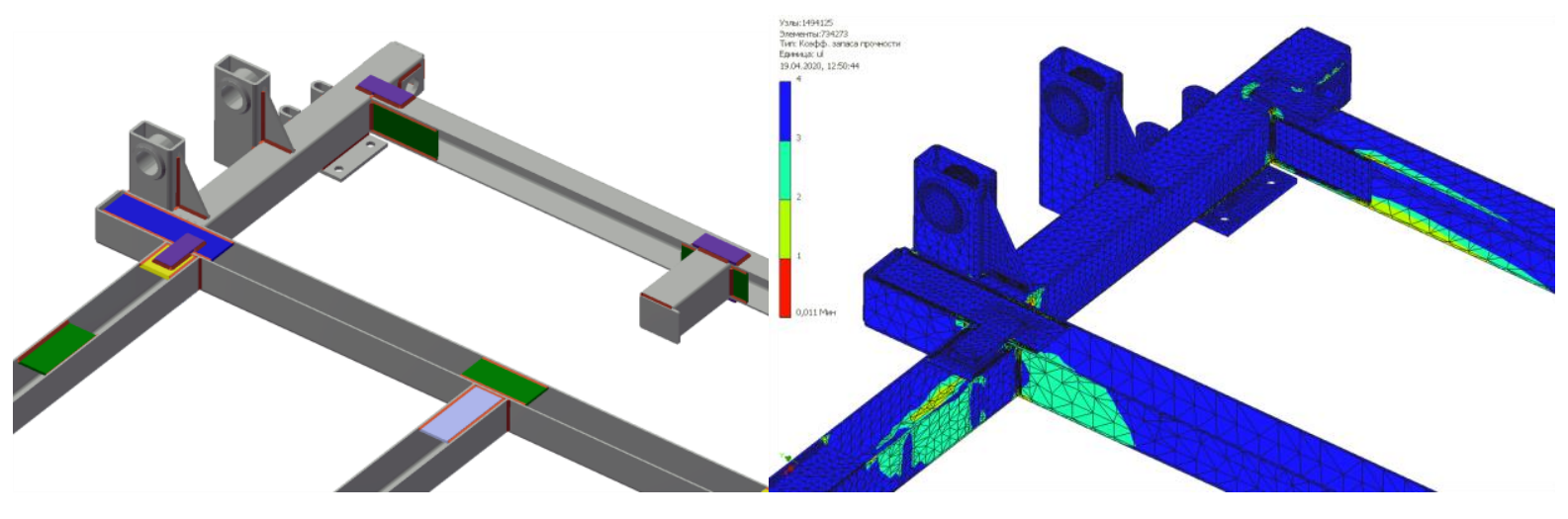

(a)

(b)

Figure 5. The safety factor calculation of the frame structure made of channels:

(a) - structures, (b) - calculation results.

When comparing the calculation results presented in figures 3 and 5, then, despite the obvious 'weakening' of the frame structure, the stresses in its elements at the same loads turned out to be approximately equal. This is explained by a decrease in the rigidity of the frame. The deformations of the frame that occur during cultivator operation have increased approximately twofold. However, this fact does not affect its performance.

At the same time, the mass of the frame is noticeably reduced. The weight of the frame in the basic version is $270.5 \mathrm{~kg}$, in the new version $-175.8 \mathrm{~kg}$.

There are also negative points. The laboriousness of manufacturing a frame has noticeably increased, and hence its cost. 


\section{Conclusion}

The methodology for designing welded frame structures proposed by the authors, implemented on the basis of Autodesk Inventor Professional, allows not only to increase the productivity of design work, but also to increase their quality.

Using the modeling of a cultivator frame as an example, Autodesk Inventor Professional demonstrated the capabilities of this program for optimizing the designed structures of engineering objects.

This work is part of the educational process [16-18], implemented at the Department of Mechanical Engineering Technology of Lipetsk State Technical University, as part of the training of future specialists for engineering enterprises.

\section{References}

[1] Ustinov A N 2010 Agricultural Machines: 2nd Ed (Moscow: IRPO "Academy") p 264

[2] Turbina B G 2007 Agreecultural machines. Agreecultural equipment. Theory and technological calculation. ed B G Turbina (Moscow: Mechanical Engineering) p 356

[3] Bosoy E S, Vernyaev O V, Smirnov I I and Sultan-Shah E G 1977 Theory, Design and Calculation of Agricultural Machines: A Textbook for High Schools of Agricultural Engineering (Moscow: Mechanical Engineering) p 568

[4] Birger I A, Shorr B F and Iosilevich G B 1993 Strength analysis of machine parts: Handbook, 4th ed (Moscow: Mechanical Engineering) p 640

[5] Dunaev P F and Lelikov O P 1998 Construction of units and parts of machines: Textbook. allowance for tech. spec. universities (Moscow: Higher school) p 447

[6] Telegin V V, Kozlov A M and Sakalo V I 2017 Solid Modeling and Dynamic Analysis of the Mechanisms of Press-forging Machines Procedia Engineering 206 pp 1258-63

[7] Telegin V, Kozlov A and Shumilova T 2018 Development and research of the rotating lever object as a dynamic model of a cycle mechanism MATEC Web Conf. International Conference on Modern Trends in Manufacturing Technologies and Equipment (ICMTMTE 2018) 22402078

[8] Ovcharenko V A 2004 Calculation of mechanical engineering problems by the finite element method: Textbook (Kramatorsk: DGMA) p 128

[9] Gallagher R. 1984 The Finite Element Method. The basics (Moscow: Mir) p 428

[10] Zienkiewicz O C 1975 The finite element method in engineering science (Moscow: Mir) p 541

[11] Zinoviev D V 2016 Design Fundamentals in Autodesk Inventor 2016, ed. Azanova M, 2nd ed. (Moscow: DMK Press) p 256

[12] Kontsevich V G 2007 Solid State Modeling of Engineering Products in Autodesk Inventor (Moscow: DMK Press) p 670

[13] Russian state standard GOST 8645-68 Rectangular steel tubes. Range (Moscow)

[14] Russian state standard GOST 380-2005 Common quality carbon steel. Grades (Moscow)

[15] Russian state standard GOST 8278-83 Roll-formed steel equal channels. Dimensions (Moscow)

[16] Telegin V V, Telegin I V and Kirichek A V 2019 Solid-state modeling and basic training of specialists in the field of mechanical engineering IOP Conf. Ser.: Mater. Sci. Eng. 483 012004

[17] Telegin V V, Telegin I V and Stepanov A S 2018 3D-Forming and Autodesk Autocad at the Initial Stage of Engineering Training of Specialists in Technical Areas International Journal of Engineering and Technology (UAE) 7 (3.5) pp 1-3

[18] Telegin V V and Telegin I V 2019 Solid Modeling in Professional Training of Specialists for Machine-Building Enterprises International Journal of Innovative Technology and Exploring Engineering (IJITEE) 8 (9S3) pp 7-9 